\title{
IGUALDADE, JUSTIÇA E TRIBUTAÇÃO
}

\author{
Equality, Justice and Taxation
}

\section{Geórgia Teixeira Jezler Campello}

Mestre em Direito pela PUC-SP. Especialista em Direito Tributário pela PUC-SP. MBA em Direito Público pela FGV-RIO. Especialista em Filosofia Contemporânea pela Faculdade do Mosteiro de São Bento da Bahia. Procuradora do Município de Salvador.

\section{Resumo}

O propósito desta investigação é analisar a igualdade, a sua relação com a justiça e os seus efeitos na tributação. Serão abordados os aspectos filosófico e jurídico, haja vista que o ideal político da igualdade não ficou apenas no campo filosófico, mas ingressou nas discussões da esfera jurídico-dogmática, por ter sido introduzido no sistema constitucional com a roupagem de princípio. Inicialmente será tratada a relação da igualdade com as teorias de justiça; em seguida, como princípio introduzido no sistema constitucional, que informa a elaboração das normas infraconstitucionais e também a sua aplicação. Serão ainda elencados os critérios para se aferir o conteúdo da igualdade. Por fim, será analisada a capacidade contributiva, medida quantificadora da igualdade ou desigualdade no campo tributário, fundamentada na igualdade geral.

Palavras-chave: Igualdade. Justiça. Igualdade tributária. Capacidade contributiva.

\section{Abstract}

This work analyzes equality, its relation to justice and its effects on taxation. The philosophical and juridical aspects will be treated, because the political ideal of equality was not only in the philosophical field, but it entered the juridical-dogmatic discussions sphere, since it was introduced in the constitutional system as a principle. Firstly, will be analyzed the relation between equality and theories of justice; and then as a principle introduced into the constitutional system which informs the elaboration of infraconstitutional norms and their application. The criteria for measuring the content of equality will also be listed. Finally, the contributive capacity will be treated as a measure of equality or inequality in tax field, based on general equality.

Keymords: Equality. Justice. Tax Equality. Contributive capacity.

\section{Sumário}

1. Introdução; 2. A igualdade e as teorias de justiça; 3. As dimensões do princípio da igualdade: igualdade perante a lei e igualdade na lei; 4. O princípio da igualdade tributária; 5. Conclusão; 6. Notas; Referências. 


\section{INTRODUÇÃO}

O presente trabalho pretende abordar a igualdade como elemento fulcral da teoria filosófica da justiça e também na sua dimensão jurídica, vez que a igualdade é a base de todo o sistema jurídico nacional.

Nessa perspectiva traz-se à tona a filosofia de Aristóteles, que consagra a justiça como a maior das virtudes e será considerada, em especial, a teoria da justiça de John Rawls, a mais relevante do século XX, por tentar conciliar dois valores morais considerados até então inconciliáveis na modernidade: a igualdade e a liberdade.

Apesar da igualdade em si mesma não portar conteúdo, é possível preenchê-lo por outras normas constitucionais, como se verá no decorrer do trabalho. A igualdade possui duas dimensões: a igualdade perante a lei e igualdade na lei ou material e a avaliação desta última requer o apontamento de critérios objetivos que lhe deem suporte, como se verá a seguir.

Será demonstrado que uma concepção contemporânea de justiça deve contemplar os valores da liberdade, da igualdade e da solidariedade e que uma tributação, nessa senda, deve, impreterivelmente, responder às exigências de capacidade econômica, calcadas na igualdade. Destarte, a igualdade geral já subsidiaria a tributação com base na capacidade contributiva, ainda que não houvesse dispositivo específico.

\section{A IGUALDADE E AS TEORIAS DE JUSTIÇA}

A igualdade é elemento central de qualquer teoria da justiça, de modo que pode-se afirmar que é isonômico o que é justo. Tem como cerne o clássico ensinamento de Aristóteles:

\footnotetext{
Pensa-se, por exemplo, que justiça é igualdade - e de fato é -, embora não o seja para todos, mas somente para a aqueles que são iguais entre si; também se pensa que a desigualdade pode ser justa, e de fato pode, embora não para todos, mas somente para a aqueles que são desiguais entre si; os defensores dos dois princípios, todavia, omitem a qualificação das pessoas às quais eles se aplicam, e por isto julgam mal; a causa disto é que eles julgam tomando-se a si mesmo como exemplo e quase sempre se é um mal juiz em causa própria. ${ }^{1}$
}

Deve-se observar que a filosofia moral de Aristóteles, lembrada no Brasil por Rui Barbosa no célebre trecho da sua Oração aos $\mathrm{Moços}^{2}$, traz uma base de fundamental importância para o estudo relacionado às instituições sociais e políticas, porquanto a discussões sobre direitos e justiça conduz sempre rumo às investigações sobre o objetivo das instituições sociais, os bens por ela destinados e o que elas valorizam, isto é, sobre a natureza da vida boa. Contudo, vale também considerar as teorias de justiça mais modernas que reconhecem o pluralismo e, nessa esteira, a possibilidade de coexistirem diversas concepções de bem.

Um expoente da filosofia política do século XX é John Rawls, que tentou construir racionalmente um conceito de justiça, tendo destaque a sua obra "Teoria da Justiça".

Rawls dedicou a sua vida a uma elaboração da teoria da justiça capaz de conjugar os dois principais valores morais do mundo moderno e aparentemente inconciliáveis na ideologia do século XX, quais sejam, a liberdade e a igualdade. Esse é o grande diferencial 
da sua teoria, de natureza contratualista em sua fundamentação e liberal-igualitária em seus compromissos normativos substantivos.

A ideia central da sua teoria da justiça como equidade é que "os princípios de justiça para a estrutura básica da sociedade constituem o objeto do acordo original." ${ }^{3}$ Nessa esteira esclarece o que seriam esses princípios:

São eles os princípios que pessoas livres e racionais interessadas em promo-
ver seus próprios interesses, aceitariam em uma situação original de igualda-
de como definidores das condições fundamentais de sua associação. Esses
princípios devem reger todos os acordos subsequente; especificam os tipos de
cooperação social que se podem realizar e as formas de governo que se po-
dem instituir. Chamarei de justiça como equidade essa maneira de encarar os
princípios de justiça. ${ }^{4}$

Assim, no lugar do contrato social, imagina uma situação - the original position - que não é uma situação histórica, mas hipotética, para justificar o seu contratualismo e os legisladores iniciais, sob o véu de ignorância, fariam as escolhas principiológicas de justiça.

Com relação ao conteúdo dos princípios da justiça, vale registrar que no primeiro parágrafo da sua teoria, Rawls define o conceito de justiça:

\begin{abstract}
A justiça é a virtude primeira das instituições sociais, assim como a verdade é dos sistemas de pensamento. Por mais elegante e econômica que seja deve-se rejeitar a teoria que não seja verdadeira; da mesma maneira que as leis e as instituições, por mais eficientes e bem organizadas que sejam, devem ser reformuladas ou abolidas se forem injustas. ${ }^{5}$
\end{abstract}

Assim, desde logo, vê-se que para Rawls a justiça é a virtude cardeal do ponto de vista das instituições políticas.

Nessa perspectiva pressupõe que na posição original ninguém escolheria jamais o princípio utilitarista ${ }^{6}$ como regente das instituições sociais. Dois princípios de justiça emergiriam do contrato hipotético:

\footnotetext{
Primeiro: cada pessoa deve ter um direito igual ao sistema mais extenso de iguais liberdades fundamentais que seja compatível com um sistema similar de liberdades para as outras pessoas.

Segundo: as desigualdades sociais e econômicas devem estar dispostas de tal modo que tanto (a) se possa razoavelmente esperar que se estabeleçam em benefício de todos como (b) estejam vinculadas a cargos e posições acessíveis a todos. ${ }^{7}$
}

A igual liberdade para todos envolve as liberdades básicas (política, de expressão, de consciência, do pensamento, direito à propriedade pessoal, etc.). Este princípio sobrepõe-se a qualquer consideração sobre utilidade geral e bem-estar social, de modo que não podem ser compensados com qualquer maior vantagem social ou econômica. Essas liberdades só podem ser confrontadas com outras liberdades fundamentais e, diante destas circunstancias, não podem ser consideradas absolutas. ${ }^{8}$

$\mathrm{Na}$ medida em que esses indivíduos passam a cooperar e gerar riquezas surgiria a necessidade de distribuir os recursos, surgindo assim, o segundo princípio.

No que se refere ao segundo princípio, a distribuição de vantagens e riqueza não precisa ser igual para todos, mas precisa ser vantajosa (princípio da diferença) e os cargos de autoridade e responsabilidade acessíveis, a todos (princípio da igualdade oportunidade). ${ }^{9}$ 
Assim, esses princípios concebem uma justiça em que todas as liberdades, oportunidades, renda, riqueza devem ser distribuídas de forma igual, a não ser que uma distribuição desigual de um desses valores seja vantajosa para todos e a desigualdade de resultado, ainda que aconteça, ocorra num ambiente de igualdade equitativa de oportunidade.

A ideia central da tese, inclusive para justificar as escolhas sob o véu da ignorância, é que a distribuição de renda e riqueza não deve ser fundamentada em fatores arbitrários do ponto de vista moral. ${ }^{10}$

O princípio da diferença elimina a indeterminação do princípio da eficiência, selecionando uma posição específica a partir da qual as desigualdades sociais e econômicas da estrutura básica devem ser julgadas.

Nas sociedades do livre mercado, não obstante atenuarem as arbitrariedades porque garantem uma igualdade perante a lei e portanto as mesmas liberdades básicas, a distribuição de renda e riqueza fica a cargo deste livre mercado, é a teoria libertária de justiça. Entretanto, essas oportunidades não seriam as mesmas, apesar de legalmente o serem, porque os que nascem em famílias mais abastadas necessariamente já teriam outro ponto de partida, mais à frente do que os que não dispusessem da mesma sorte.

Dessa forma, apesar da interpretação liberal ser preferível ao sistema da liberdade natural, ainda possui inconsistências, pois os dotes naturais, o acaso e circunstancias sociais, históricas e familiares influenciam e desequilibram a oferta de oportunidades. É necessária uma interpretação que amenize os resultados da loteria natural, ou seja, que corrija as diferenças sociais e econômica.

A concepção meritocrática pode cumprir esse papel, mas ela atenta para o fato de que, ainda que se consiga que todos partam do mesmo ponto, certamente os vencedores serão os mais velozes. E ser um veloz corredor não é mérito próprio da pessoa, mas contingente sob o ponto de vista moral, do mesmo modo que integrar uma família abastada o é.

Essas contingências sociais conduzem impreterivelmente a uma arbitrariedade moral que compromete tanto a teoria libertária quanto a meritocrática. Essa ideia de Rawls gerou críticas no sentido de que a solução portanto seria limitar os indivíduos com mais aptidões.

Todavia, Rawls propõe a teoria igualitária de justiça, também distributiva como as precedentes, mas com uma peculiaridade que é o princípio da diferença, aplicado justamente para corrigir as distorções na distribuição desigual de aptidões sem limitar os mais talentosos, mas reconhecendo que os prêmios não lhes pertencem exclusivamente, mas devem ser compartilhados com aqueles que não têm os mesmos dotes. ${ }^{11}$

O valor ou proveito da liberdade não é igual para todos (a menos que fosse visto apenas pelo aspecto formal) e deve ser dividido igualmente entre todos. Entretanto, quem tem mais riqueza e renda tem meios mais efetivos para alcançar os seus fins, decorrendo daí a necessidade de se combinar liberdades fundamentais iguais com princípios que objetivem regular certos bens primários vistos como meios polivalentes para promover os fins dos indivíduos e isso é possível incluindo valor equitativo às liberdades políticas. Desse modo, o valor das liberdades políticas deve ser igual ou suficientemente igual, no sentido de que 
todos tenham oportunidade equitativa de assumir um cargo público e influenciar os resultados de decisões políticas.

A justiça, conforme a premissa da teoria de John Rawls, é calçada num conjunto de normas e instituições que governam determinada sociedade, sendo que numa sociedade plural não há como pensar em princípios de justiça que não contemplem ou garantam a solidariedade social, razão pela qual afirma Marciano Seabra de Godói, ao observar a relação da teoria da justiça de Rawls com a solidariedade social, que "uma concepção contemporânea de justiça no quadro das sociedades atuais deve contemplar os valores da liberdade da igualdade e da solidariedade."12

E o que se espera de um direito tributário em termos de solidariedade é que os impostos respondam às exigências de capacidade econômica, ${ }^{13}$ predicadas na igualdade.

Rawls reconhece inclusive que a tributação pode "corrigir gradual e continuamente a distribuição de riqueza e impedir a concentração de poder que prejudiquem o valor equitativo da liberdade política e da igualdade equitativa de oportunidade", ${ }^{14}$ pois quando a desigualdade de riqueza atinge certo limite, as próprias instituições e as mesmas oportunidades de educação e cultura para pessoas de motivação semelhante são ameaçadas.

A tributação tem um importante papel na obtenção de recursos para que se cumpra o princípio da diferença e, portanto, na distribuição de riquezas na sociedade.

A igualdade é relevante tanto na fundamentação das teorias filosóficas de justiça quanto nos ordenamentos jurídicos. O ideal político da igualdade não ficou apenas no campo filosófico, mas ingressou nas discussões da esfera jurídico-dogmática, por ter sido introduzido no sistema constitucional com a roupagem de princípio.

\section{AS DIMENSÕES DO PRINCÍPIO DA IGUALDADE: IGUALDADE PERANTE A LEI E IGUALDADE NA LEI}

A igualdade ou isonomia é princípio central de todo o sistema constitucional brasileiro; é um preceito básico do Estado Democrático de Direito, voltado tanto para o aplicador quanto para o legislador; é, por excelência uma clausula pétrea.

O termo "igualdade" deu azo a diversas significações. A depender do contexto, da relação com o objeto e da utilização do termo pode gerar diversos sentidos, o que se dá comumente com os signos, confirmando a importância de se recorrer às dimensões em que a linguagem se apresenta.

Humberto Ávila alerta que a discordância entre os autores sobre os sentidos da igualdade por vezes é aparente, bem como podem haver diversos sentidos coexistentes a depender da distinta funcionalidade da norma e que podem as diversas dimensões da igualdade atuar conjuntamente. Sublinha que é possível aferir três vertentes normativas para o termo, quais sejam: igualdade-postulado; igualdade-princípio e igualdade-regra: 
ser alcançado (igualdade-princípio); pode-se, ainda, empregá-lo para referir a norma que proíbe o emprego de determinadas medidas de comparação (igualdade-regra). ${ }^{15}$

Assim, a igualdade pode ser uma metanorma, quando direciona a aplicação isonômica de qualquer princípio substancial, pois todos aqueles protegidos por um princípio têm igualdade de direitos. O princípio deve ser aplicado de forma isonômica. A igualdade aqui não é objeto de ponderação, mas critério de aplicação de outras normas. A igualdade como princípio é igualdade como norma, objeto de aplicação na busca de um estado ideal de igualdade. Já a igualdade como regra é também igualdade como norma, objeto de aplicação, mas que pré-exclui do Poder Legislativo o exercício da competência, utilizando determinado método de comparação. ${ }^{16}$

As divergências acerca do conteúdo da igualdade, que já justificou historicamente conquistas humanísticas, mas também grandes atrocidades, torna fundamental a busca na Constituição vigente dos valores e ideologia firmados por meio dos princípios constitucionais, para que se possa extrair e determinar o conteúdo da igualdade. A igualdade em si não porta conteúdo, que vai sendo preenchido por outras normas constitucionais.

O direito fundamental geral de igualdade vem previsto na Constituição de 88 , no caput do seu artigo $5^{\circ}$ :

\begin{abstract}
Artigo $5^{\circ}$ Todos são iguais perante a lei, sem distinção de qualquer natureza, garantindo-se aos brasileiros e aos estrangeiros residentes no País a inviolabilidade do direito à vida, à liberdade, à igualdade, à segurança e à propriedade, nos termos seguintes:
\end{abstract}

Superada a tese de que a igualdade se operava apenas na aplicação da lei, ganha aceitação a ideia de que vincula o legislador, como previne Alexy, pois caso assim não fosse, seria "incompatível com a ideia dos direitos fundamentais como expressão da desconfiança com relação ao legislador o que inclui a submissão das leis por ele criadas a um controle em face dos direitos fundamentais." ${ }^{17}$

Para se chegar a uma vinculação substancial do legislador deve-se distinguir o tratamento entre iguais e desiguais não como exigência relativa à forma lógica das normas, mas como atinente ao seu conteúdo. ${ }^{18}$

A igualdade só é aferível por determinados critérios, daí a sua relatividade, além de recair sempre sobre os valores jurídicos direcionados ao critério para diferenciar e às características relevantes para agrupar os objetos em relevo. De regra as divergências giram nesta seara material.

O princípio da igualdade formal não aponta critérios e portanto não conflita com a igualdade material; é norma de tratamento, pressupondo, segundo Misabel Derzi:

\footnotetext{
- a dessemelhança 'relativa' entre todos os seres;

- a possibilidade de comparação entre os seres, que podem ser classificados como 'relativamente' iguais, segundo um certo critério ou aspecto determinado;

- o caráter axiológico do critério, variável historicamente, que só pode ser objetivamente colhido a partir da Constituição de cada país (ou de normas fundamentais equivalentes). ${ }^{19}$
}

A igualdade, portanto, possui duas dimensões: a igualdade perante a lei e igualdade 
na lei ou material, sendo que para a análise desta última é necessário o estabelecimento de critérios objetivos que lhe deem suporte. Os critérios também são relevantes para que as opções do legislador sejam analisadas. Dois são, sob o ângulo da igualdade na lei, os aspectos a serem considerados: como proibição de distinguir e como dever de distinguir.

José Casalta Nabais enfatiza que, ultrapassado o positivismo legalista, o atual princípio constitucional da igualdade vincula o legislador, obrigando-o a não fazer discriminações arbitrárias ou igualações carentes de justificações ou fundamentos material ou racional, devendo tratar igualmente os iguais e desigualmente os desiguais, cumprindo nessa senda com a igualdade na lei. De outro lado, obriga ainda o senhor da lei de forma positiva a fazer discriminações com o fito de criar, seja um mínimo de igualdade como ponto de partida ou igualdade de oportunidades ou de chances, a depender do grau de necessidade primárias dos indivíduos, como alimentação, vestuário, habitação, saúde, segurança social e educação, seja um mínimo de igualdade como ponto de chegada ou de resultados, dependendo das referidas necessidades primárias e de outros fatores, que configura a "igualdade pela lei." 20

Dworkin, que considera a igualdade o motor do liberalismo, faz uma distinção interessante sobre a igualdade, qual seja: o direito a igual tratamento (equal treatment), que seria o direito à igual distribuição de certa oportunidade, recurso ou encargo (todo cidadão tem o direito a um voto igual em uma democracia); bem como o direito ao tratamento como igual (treatment as equal), direito de ser tratado com o mesmo respeito e consideração que qualquer outra pessoa, asseverando que o direito ao tratamento como igual, de tratar os cidadãos com o mesmo valor, é fundamental e o direito a igual tratamento seria derivado. Em alguma circunstância eles coincidem, mas nem sempre. ${ }^{21}$

O princípio da igualdade genérica como já ressaltado está contido na formulação do artigo $5^{\circ}$, caput, da Constituição Federal; já no domínio do direito tributário consta do artigo 150 , II, com o desiderato de garantir uma tributação justa, não discriminando os contribuintes que estiverem na mesma situação.

A interpretação da igualdade geral prevista no caput do artigo $5^{\circ}$ da Constituição vai sendo orientada por outros dispositivos constitucionais, a exemplo dos artigos $1^{\circ}, 3^{\circ}, 170 \mathrm{e}$ 193, obstaculizando assim uma interpretação carregada de subjetivismo, apesar da abertura do termo.

Não que seja fácil lidar com a isonomia, que necessita de critérios para a sua aferição, razão pela qual Celso Antônio Bandeira de Mello apontou para o fato de que entre os iguais e desiguais de Aristóteles há um vácuo de incertezas que pode propiciar injustiças, de sorte que é fundamental se estabelecer qual o critério manipulável para verificar a distinção e tratamentos jurídicos diversos a pessoas e situações sem que haja violação à igualdade. ${ }^{22}$

Hans Kelsen, na sua visão positivista do direito, negou a possibilidade de uma justiça material, distinguiu entre igualdade perante a lei e igualdade na lei, restringindo a igualdade ao primeiro aspecto. Traz, portanto, parâmetros para se aferir igualdade, quais sejam aqueles determinados expressamente pela Constituição, o que supõe uma aplicação correta da lei. ${ }^{23}$ 
Contudo, é de se ver que há situações em que diferenciações baseadas em convicção religiosa ou de sexo, por exemplo, que são expressos na Carta Magna como fatos ou situações abarcados pelos valores de igualdade e liberdade, podem justificar uma desequiparação sem que se viole a isonomia, porque a diferenciação de tratamento muitas vezes está calcada em valores também constitucionais, ainda que implícitos, impassíveis de uma aplicação hierarquizada ou absoluta, sem que isso represente a diminuição do âmbito de proteção de ambos os direitos ou valores em que a diferenciação se baseia.

A lei como reguladora da vida social não pode privilegiar ou perseguir, mas tratar equitativamente todos aqueles abrangidos por ela de forma análoga. Este é o conteúdo político-ideológico absorvido pelo princípio da isonomia e positivado nos mais diversos sistemas jurídicos. $^{24}$

A lei, abstratamente, deve ser a mesma para todos, apenas razões justificáveis e compatíveis com a Constituição podem estabelecer uma diferenciação de tratamento em função delas. Assim, desequiparação vazia, por puro preconceito, não encontra guarida nos valores consagrados constitucionalmente.

Celso Antônio Bandeira de Mello estabelece os seguintes critérios para a aferição da violação da isonomia:

Há ofensa ao preceito constitucional da isonomia quando:

I - A norma singulariza atual e definitivamente um destinatário determinado, ao invés de abranger uma categoria de pessoas, ou uma pessoa futura indeterminada.

II - A norma adota como critério discriminador, para fins de diferenciação de regimes, elemento não residente nos fatos, situações ou pessoas por tal modo desequiparadas. É o que ocorre quando pretende tomar o fator tempo - que não descansa no objeto - como critério diferencial.

III - A norma atribui tratamentos jurídicos diferentes em atenção ao fator de discrímen adotado que, entretanto, não guarda relação de pertinência lógica com a disparidade de regimes outorgados.

IV - A norma supõe relação de pertinência lógica existente em abstrato, mas o discrímen estabelecido conduz a efeitos contrapostos ou de qualquer modo dissonantes dos interesses protegidos constitucionalmente.

$\mathrm{V}$ - A interpretação da norma extrai dela distinções, discrímens, desequiparações que não foram professadamente assumidos por ela de modo claro, ainda que por via implícita. ${ }^{25}$

Misabel Derzi preceitua os critérios de comparação da igualdade material, sem que se quebre a igualdade formal, da seguinte forma:

1. na proibição de distinguir (universalmente) na aplicação da lei em que o valor básico é a segurança jurídica;

2. na proibição de distinguir no teor da lei, vedação que salvaguarda valores democráticos como a abolição de privilégios e de arbítrio. Os princípios da generalidade e da universalidade estão a seu serviço e têm como destinatários todos aqueles considerados iguais;

3. no dever de distinguir no conteúdo da lei entre desiguais, e na medida dessa desigualdade. No Direito Tributário, o critério básico que mensura a igualdade ou a desigualdade é a capacidade do contribuinte;

4. no dever de considerar as grandes desigualdades econômico-materiais advindas dos fato, com o fim de atenuá-las e restabelecer o equilíbrio social. A progressividade dos tributos favorece a igualação das díspares condições concretas, em vez de conservá-las ou acentuá-las; 


\begin{abstract}
5. na possibilidade de derrogações parciais ou totais do princípio da capacidade contributiva pelo acolhimento de outros valores constitucionais como critérios de comparação, os quais podem inspirar a progressividade, regressividade, isenções e benefícios, na busca de um melhor padrão de vida para todos, dentro dos planos de desenvolvimento nacional integrado e harmonioso. ${ }^{26}$
\end{abstract}

A igualdade é a relação entre dois ou mais sujeitos em razão de uma medida, de um critério que serve a uma finalidade. Sempre que se compara é por algum motivo ${ }^{27}$, sendo que o fundamento da desequiparação é de capital importância.

Canotilho observa que o princípio da igualdade é não apenas um princípio de Estado de direito, mas um princípio de Estado social, devendo ser considerado um princípio de justiça social, pois liga-se com a política de justiça social e com a concretização das imposições constitucionais tendentes à efetivação dos direitos econômicos, sociais e culturais, além de inerente à própria ideia de igual dignidade social (e de igual dignidade da pessoa humana). ${ }^{28}$

Transpondo esse desenlace para os dispositivos constitucionais pátrios, podem ser destacados o artigo $3^{\circ}$, I que dispõe consistirem objetivos fundamentais da República Federativa do Brasil, "constituir uma sociedade livre, justa e solidária", mesmos princípios que marcaram a Revolução Francesa (liberdade, igualdade e fraternidade), cujo compromisso axiológico permeia toda a Constituição.

No artigo $1^{\circ}$ resta consignado que a República Federativa do Brasil "constitui-se em Estado Democrático de Direito", ou seja, a República, o governo do povo, que visa construir uma sociedade livre, justa e solidária constitui-se num Estado Democrático de Direito. Esse Estado de Direito supera o Estado meramente formal e busca a justiça social, que marca a Ordem Econômica que "tem por fim assegurar a todos existência digna, conforme os ditames da justiça social" (artigo 170) e a Ordem Social que "tem como base o primado do trabalho, e como objetivo o bem-estar e a justiça social" (artigo 193).

O Estado de direito material serve aos objetivos de justiça consignados na Constituição Federal, como nos artigos $3^{\circ}, I, 170$ e 193, sendo que essa justiça se efetiva no princípio da igualdade (artigos. $5^{\circ}, \mathrm{I}, 7^{\circ}$ XXXIV, 14, 37, XXI, 150, II, 196, e 206) e como direitos e garantias fundamentais (artigos $5^{\circ}, 6^{\circ}$ e $7^{\circ}$ ).

Nesse giro interpretativo, a igualdade vai adquirindo o seu conteúdo no sistema constitucional.

A igualdade perante a lei ou formal é relevante, mas insuficiente se não enriquecida com uma igualdade do conteúdo da lei ou igualdade material.

Marciano Seabra de Godoi enfoca exatamente que as democracias ocidentais (e não nas democracias marxistas) prometeram a igualdade de fato, significada no Estado Democráticos de Direito e no Estado Social, e conclui que das obras dos grandes constitucionalistas e filósofos políticos contemporâneos:

Tanto nas ordens constitucionais concretas quanto nas fundamentações filosóficas e teorias da justiça, é fundamental o papel da igualdade enquanto redutora das desigualdades fáticas (criadora de igualdade substancial diante dos bens da vida, culturais, econômicos e sociais), especialmente daquelas desigualdades moralmente arbitrárias (Rawls) e vinculadas a circunstâncias sociais e não à pessoa do indivíduo. ${ }^{29}$ 
José Afonso da Silva também chamou atenção para o fato de que a igualdade presente no caput do artigo $5^{\circ}$, que se confunde com a isonomia formal no sentido de que a lei e sua aplicação tratam a todos igualmente sem considerar a distinção de grupos, deve ter a sua interpretação enriquecida por outros dispositivos constitucionais, não pode ser tão estreita e, "especialmente, com as exigências de justiça social, objetivo da ordem econômica e da ordem social". ${ }^{30}$

A igualdade é dever-ser em constante elaboração, orientada pelo ideal de justiça e nesse ângulo ganha a dinamicidade implementada pelos demais dispositivos constitucionais que confirmam ter a Constituição instituído um Estado Democrático de Direito com forte cunho social, devendo o princípio da igualdade ser interpretado neste ritmo e ambiente.

\title{
4. O PRINCÍPIO DA IGUALDADE TRIBUTÁRIA
}

A igualdade tributária está prevista no artigo 150, II, da Constituição Federal que consigna que:

\begin{abstract}
Artigo 150. Sem prejuízo de outras garantias asseguradas ao contribuinte, é vedado à União, aos Estados, ao Distrito Federal e aos Municípios:

$[\ldots]$

II - instituir tratamento desigual entre contribuintes que se encontrem em situação equivalente, proibida qualquer distinção em razão de ocupação profissional ou função por eles exercida, independentemente da denominação jurídica dos rendimentos, títulos ou direitos;
\end{abstract}

Os enfoques apontados com relação à igualdade geral refletem na esfera tributária, assim como em outros ramos do Direito, que elegem os seus princípios específicos em busca da justiça. ${ }^{31}$ No campo tributário, a capacidade contributiva é critério justo de discriminação, considerando a riqueza de cada contribuinte. $O$ fator de discriminação é revelado pelo aspecto material da hipótese tributária.

Sempre que um princípio é positivado representa que todos devem praticar atos que gerem os efeitos dele decorrente, não cabendo ao legislador restringi-lo por meio de diferenciações, utilizando-se de medidas e comparações incompatíveis com a realização dessas normas constitucionais.

A capacidade contributiva é uma das concepções de igualdade possíveis; é a medida, critério mensurador da igualdade no campo tributário. É dedutível do princípio da igualdade geral e não necessariamente da igualdade tributária prevista no artigo 150, II, da Constituição, que também deriva da igualdade geral.

A finalidade, entendida como um estado de fato que precisa ser atingido e que subsidia as escolhas das medidas de comparação, está prevista na Constituição. Com relação ao Direito Tributário, a Constituição prevê a finalidade fiscal e extrafiscal. Na primeira, a medida deve ser aferida por elementos presentes nos próprios contribuintes como a sua capacidade contributiva; na extrafiscal, como a finalidade pública a ser atingida é autônoma, as medidas de comparação estão fora dos contribuintes, a exemplo da finalidade de se fomentar o desenvolvimento de uma certa região ou proteger o meio ambiente, dentre outras.

No Direito Tributário, o emprego desse super valor que supera as fronteiras de um 
simples princípio ${ }^{32}$, que é a igualdade, ganha um viés mais simples, porque o critério é objetivo no sentido de que pessoas do mesmo padrão monetário devem ser tributadas na mesma proporção. Tem-se como standard a variação da base de cálculo, de modo que as ingerências subjetivas neste caso ficam bastante reduzidas, diante do bloqueio das normas que direcionam o intérprete na aplicação da isonomia.

Pode-se concluir, ainda em matéria tributária, que a igualdade enquanto proibição de distinguir legalmente, representa que a norma deve estipular pressupostos legais e idênticas consequências, sem discriminar por conta de sexo, raça, credo religioso, no sentido de se cumprir a proibição de não discriminar. Não que a proibição seja absoluta, pois a Constituição já o relativiza ao estabelecer as imunidades. Por outro lado, a imposição da tributação para que se cumpra a capacidade contributiva, distinguindo os contribuintes pela medida de suas riquezas representa a efetivação do princípio da igualdade na lei como um dever de distinguir. São os aspectos negativo e positivo da isonomia substancial ou no teor da norma. ${ }^{33}$

Na esfera tributária devem ser aplicados os dois aspectos: o negativo de não distinguir, ou seja, cobrar o mesmo dos contribuintes que estiverem na mesma situação; bem como o aspecto positivo, de suma importância para se cumprir a igualdade em matéria tributária, com base na capacidade contributiva no campo fiscal, aplicável a todos os impostos, sempre que possível, buscando-se as medidas mais adequadas para cumpri-la.

Nesse prisma, a igualdade geral já subsidiaria a tributação com base na capacidade contributiva, ainda que não houvesse dispositivo específico.

A isonomia nada mais é do que a igualdade de direitos e deveres, sendo o tributo dever de caráter obrigacional e cunho patrimonial, devendo-se considerar na sua instituição e cobrança a capacidade de contribuir.

Na tributação extrafiscal, contudo, a prioridade não é arrecadatória, mas ordinatória e de busca do atingimento de fins sociais ou econômicos, de sorte que se admite que o legislador imprima uma tributação progressiva ou regressiva, visando atingir esses fins e, nesta senda, a capacidade contributiva recua; todavia, essa derrogação não representa afastamento da igualdade formal, porque as pessoas beneficiadas ou sobrecarregadas pela carga tributária de finalidades extrafiscais não estão na mesma categoria dos demais contribuintes, não restando violada a regra do igual tratamento àqueles da mesma categoria essencial.

Ainda que fundamentada na sua função extrafiscal, social ou redistributiva, a tributação deve ter em conta a não tributação do mínimo vital e a não utilização do tributo com efeito do confisco, que também são facetas da igualdade no campo tributário.

No Direito Tributário, o critério quantificador da igualdade ou desigualdade é a capacidade contributiva, prevista no $\S 1^{\circ}$ do artigo 145 da Constituição Federal, critério específico de justiça para se atingir a igualdade dentro do sistema tributário. É princípio informador e conformador da estrutura do sistema tributário, de modo que antecede à aplicação da igualdade tributária (artigo 150, II, Constituição Federal), razão pela qual a capacidade contributiva está baseada na igualdade geral e não na igualdade especifica tributária. 


\section{CONCLUSÃO}

1. Um dos objetivos buscados pela República Federativa, que se constitui em Estado Democrático de Direito (artigo $1^{\circ}$ da Constituição Federal), é a construção de uma sociedade livre, justa e solidária (artigo $3^{\circ}$, I, da Constituição Federal), objetivo que deve ser considerado também em matéria de tributação, especialmente no que se refere ao dever de pagar impostos, de modo que cada um contribuirá com o que puder visando o bem de todos.

2. No contexto do Estado Democrático de Direito cada cidadão deve suportar a carga tributária na proporção da sua capacidade de contribuir com os gastos públicos, de modo a atender ao princípio da igualdade no campo tributário.

3. A igualdade no campo tributário decorre da igualdade geral que é um princípio estruturante do sistema constitucional e se traduz não apenas numa igualdade formal, perante a lei, mas numa igualdade material, igualdade na lei, que vincula o legislador.

4. Para a análise da igualdade na lei é necessário estabelecer critérios objetivos, que permitam analisar as opções do legislador. Dois são, sob o ângulo da igualdade na lei, os aspectos considerados: proibição de distinguir e dever de distinguir.

5. A isonomia nada mais é do que a igualdade de direitos e deveres, sendo o tributo dever de caráter obrigacional e cunho patrimonial, devendo-se considerar na sua instituição e cobrança a capacidade de contribuir.

\section{NOTAS}

1. ARISTÓTELES. A política. Brasília: UNB, 1985, Livro II, Cap. V, $1280 \mathrm{~b}$.

2. "A regra da igualdade não consiste senão em quinhoar desigual- mente aos desiguais, na medida em que se desigualam. Nesta desigualdade social, proporcionada à desigualdade natural, é que se acha a verdadeira lei da igualdade. O mais são desvarios da inveja, do orgulho, ou da loucura. Tratar com desigualdade a iguais, ou a desiguais com igualdade, seria desigualdade flagrante, e não igualdade real. Os apetites humanos conceberam inverter a norma universal da criação, pretendendo, não dar a cada um, na razão do que vale, mas atribuir o mesmo a todos, como se todos se equivalessem." (BARBOSA, Rui. Oração aos moços. 5.ed.Rio de Janeiro: Casa de Rui Barbosa, 1999, p.26).

3. RAWLS, John. Uma teoria da justiça. São Paulo: Martins Fontes, 2000, p.12-13.

4. RAWLS, John. Uma teoria da justiça. São Paulo: Martins Fontes, 2000, p.14.

5. RAWLS, John. Uma teoria da justiça. São Paulo: Martins Fontes, 2000, p.4.

6. O utilitarismo preceitua que uma ação é justa na medida em que ela maximiza o bem estar para o maior número de pessoas, ainda que outras sejam sacrificadas. (benefício x sacrifício). A cooperação social sob o aspecto utilitarista reside na extensão da escolha para a sociedade da escolha para um único ser humano.

7. RAWLS, John. Uma teoria da justiça. São Paulo: Martins Fontes, 2000, p.73.

8. RAWLS, John. Uma teoria da justiça. São Paulo: Martins Fontes, 2000, p.74-75. É difícil fazer a especificação completa da lista dessas liberdades, segundo Rawls, sem considerar as circunstancias sociais, econômicas e tecnológicas especificas de cada sociedade. Contudo a forma geral da lista de liberdades pode ser especificada com exatidão suficiente para sustentar essa concepção de justiça. As 
liberdades ausentes da lista, como o direito a certos tipos de propriedade - como a dos meios de produção - e a liberdade contratual como entendida pela doutrina do laissez-faire não são fundamentais, de modo que não estão protegidas pelo primeiro princípio.

9. RAWLS, John. Uma teoria da justiça. São Paulo: Martins Fontes, 2000, p.74.

10. SANDEL, Michael J. Justiça. O que é fazer a coisa certa. 8.ed.Rio de Janeiro: Civilização Brasileira, 2012, p.190.

11. SANDEL, Michael J. Justiça. O que é fazer a coisa certa. 8a ed. Rio de Janeiro: Civilização Brasileira, 2012, p. 192

12. GODOI, Marciano Seabra de. Tributo e solidariedade social. In solidariedade Social e tributação. Coordenação Marco Aurélio Graco e Marciano Seabra Godói. São Paulo: Dialética, 2005, p. 149

13. GODOI, Marciano Seabra de. Tributo e solidariedade social. In solidariedade Social e tributação. Coordenação Marco Aurélio Graco e Marciano Seabra Godói. São Paulo: Dialética, 2005, p. 160

14. RAWLS, John. Uma teoria da justiça. São Paulo: Martins Fontes, 2000, p.345-346

15. ÁVILA, Humberto. Teoria da igualdade tributária. 3.ed. São Paulo: Malheiros, 2015, p.139.

16. ÁVILA, Humberto. Teoria da igualdade tributária. 3.ed. São Paulo: Malheiros, 2015, p.139; 141.

17. ALEXY, Robert. Teoria dos direitos fundamentais. Tradução de Afonso Virgílio da Silva. São Paulo: Malheiros, 2008, p.395.

18. ALEXY, Robert. Teoria dos direitos fundamentais. Tradução de Afonso Virgílio da Silva. São Paulo: Malheiros, 2008, p.399.

19. BALEEIRO, Aliomar. Limitações constitucionais ao poder de tributar. 8.ed. Atualizada por Misabel de Abreu Machado Derzi. Rio de Janeiro: Forense, 2010, p.855

20. NABAIS, José Casalta. O Dever Fundamental de Pagar Impostos - Contributo para a compreensão constitucional do estado fiscal contemporâneo. Coimbra: Almedina, 2015, p.436

21. DWORKIN, Ronald. Levando os direitos a sério. Tradução de Nelson Boeira. São Paulo: Martins Fontes, 2002, p.349-350.

22. BANDEIRA DE MELLO, Celso Antônio. Conteúdo jurídico do princípio da igualdade. 3.ed. São Paulo: Malheiros, 2012, p.11.

23. A igualdade dos indivíduos sujeitos à ordem jurídica, garantida pela Constituição, não significa que aqueles devam ser tratados por forma igual nas normas legisladas com fundamento na Constituição, especialmente nas leis. Não pode ser uma tal igualdade aquela que se tem em vista, pois seria absurdo impor os mesmos deveres e conferir os mesmos direitos a todos os indivíduos sem fazer quaisquer distinções, por exemplo, entre crianças e adultos, sãos de espírito e doentes mentais, homens e mulheres. Quando na lei se vise a igualdade, a sua garantia apenas pode realizar-se estatuindo a Constituição, com referência a diferenças completamente determinadas, como talvez as diferenças de raça, de religião, de classe ou de patrimônio, que as leis não podem fazer acepção das mesmas, quer dizer: que as leis em que forem feitas tais distinções poderão ser anuladas como inconstitucionais. Se a Constituição não fixa distinções bem determinadas que não possam ser feitas nas leis relativamente aos indivíduos, e se a mesma Constituição contém uma fórmula proclamando a igualdade dos indivíduos, esta igualdade constitucionalmente garantida a custo poderá significar algo mais do que a igualdade perante a lei. Com a garantia da igualdade perante a lei, no entanto, apenas se estabelece que os órgãos aplicadores do Direito somente podem tomar em conta aquelas diferenciações que sejam feitas nas próprias leis a aplicar. Com isso, porém, apenas se estabelece o princípio, imanente a todo o Direito, da juridicidade da aplicação do Direito em geral e o princípio imanente a todas as leis da legalidade da aplicação das leis, ou seja, apenas se estatui que as normas devem ser aplicadas de conformidade com as normas. (KELSEN, Hans. Teoria 
pura do direito. 6.ed. São Paulo: Martins Fontes, 1998, p.99).

24. BANDEIRA DE MELLO, Celso Antônio. Conteúdo jurídico do princípio da igualdade. 3.ed. São Paulo: Malheiros, 2012, p.10.

25. BANDEIRA DE MELLO, Celso Antônio. Conteúdo jurídico do princípio da igualdade. 3.ed. São Paulo: Malheiros, 2012, p.47-48.

26. BALEEIRO, Aliomar. Limitações constitucionais ao poder de tributar. 8.ed. Atualizada por Misabel de Abreu Machado Derzi. Rio de Janeiro: Forense, 2010, p.859.

27. ÁVILA, Humberto. Teoria da igualdade tributária. 3.ed. São Paulo: Malheiros, 2015, p.43.

28. CANOTILHO, J. J Gomes. Direito constitucional e teoria da Constituição. 7.ed. Coimbra: Almedina, 2003, p.430.

29. GODOI, Marciano Seabra de. Justiça, igualdade e direito tributário. São Paulo: Dialética, 1999, p.155.

30. SILVA, José Afonso da. Curso de direito constitucional positivo. 32.ed. São Paulo: Malheiros, 2008, p.214-215.

31. TIPKE, Klaus; YAMASHITA, Douglas. Justiça fiscal e princípio da capacidade contributiva. São Paulo: Malheiros, 2002, p.21.

32. CONTI, José Mauricio. Princípios tributários da capacidade contributiva e da progressividade. São Paulo: Dialética, 1997, p.25.

33. DERZI, Misabel; COELHO, Sacha Calmon Navarro. Do imposto sobre a propriedade predial e territorial urbana. São Paulo: Saraiva, 1982, p.58-61.

\section{REFERÊNCIAS}

ALEXY, Robert. Teoria dos direitos fundamentais. Tradução de Afonso Virgílio da Silva. São Paulo: Malheiros, 2008.

AMARO, Luciano. Direito tributário brasileiro. 12.ed. São Paulo: Saraiva, 2006.

ARAÚJO, Clarice Von Oertzen de. Semiótica do direito. São Paulo: Quartier Latin, 2005.

ARISTÓTELES. A política. Tradução de Mário da Gama Kury. Brasília: UNB, 1985.

Ética a Nicômaco. Os Pensadores. Tradução de Leonel Vallandro e Gerd Bornheim. v. IV. São Paulo: Abril Cultural, 1973.

ÁVILA, Humberto. Teoria da igualdade tributária. 3.ed. São Paulo: Malheiros, 2015.

BALEEIRO, Aliomar. Direito tributário brasileiro. 11.ed. Atualização de Mizabel Derzi. Rio de Janeiro: Forense, 2009.

Limitações constitucionais ao poder de tributar. 8.ed. Atualizada por Misabel de Abreu Machado Derzi. Rio de Janeiro, 2010

BANDEIRA DE MELLO, Celso Antônio. Conteúdo Jurídico do Princípio da Igualdade. 3a ed. São Paulo: Malheiros, 2012. 
BARBOSA, Rui. Oração aos moços. 5.ed. Rio de Janeiro: Casa de Rui Barbosa, 1999.

BARRETO, Aires F. Curso de direito tributário municipal. São Paulo: Saraiva, 2009.

BECHO, Renato Lopes. Filosofia do direito tributário. São Paulo: Saraiva, 2009.

BECKER, Alfredo Augusto. Teoria geral do direito tributário. 2.ed. São Paulo: Noeses, 2007.

BENTHAM, Jeremy. Princípios da moral e da legislação. Os Pensadores. Tradução de Luiz João Baraúna. São Paulo: Abril Cultural, 1974.

BOBBIO, Norberto. Estado, governo, sociedade. Para uma teoria geral da política. Tradução de Marco Aurélio Nogueira. 14.ed. São Paulo: Paz e Terra S/A, 2007.

Liberalismo e democracia. 6.ed. Tradução de Marco Aurélio Nogueira. São Paulo: Brasiliense, 2000.

O futuro da democracia. Uma defesa das regras do jogo. 2.ed. Tradução de Marco Aurélio Nogueira. Rio de Janeiro: Paz e Terra, 1986.

Teoria do ordenamento jurídico. 6.ed. Tradução de Maria Celeste Cordeiro Leite dos Santos. Brasília: UNB, 1995

BONAVIDES, Paulo. Curso de direito constitucional. 26.ed. São Paulo: Malheiros, 2011.

Do Estado liberal ao Estado social. 7.ed.São Paulo; Malheiros, 2001.

CANOTILHO, J. J Gomes. Direito constitucional e teoria da Constituição. 7.ed. Coimbra: Almedina, 2003

CARVALHO, Paulo de Barros. Direito tributário, Linguagem e Método. 3a ed. São Paulo: Noeses, 2009.

CARRAZZA, Elizabeth Nazar. IPTU e Progressividade. Igualdade e Capacidade Contributiva. Curitiba: Juruá, 2000.

CONTI, José Mauricio. Princípios Tributários da Capacidade Contributiva e da Progressividade. São Paulo: Dialética, 1997.

COSTA, Regina Helena. Princípio da Capacidade Contributiva. 4a ed. São Paulo: Malheiros, 2012.

COPI, Irvin M. Introdução à lógica. Tradução de Álvaro Cabral. 2.ed. São Paulo: Mestre Jou, 1978.

DERZI, Misabel; COELHO, Sacha Calmon Navarro. Do imposto sobre a propriedade predial e territorial urbana. São Paulo: Saraiva, 1982

DWORKIN, Ronald. Levando os direitos a sério. Tradução de Nelson Boeira. São Paulo: Martins Fontes, 2002,

FERRAZ JR., Tércio Sampaio. Introdução ao Estudo do Direito. 6a ed. São Paulo: 2008. 
GODOI, Marciano Seabra de. Justiça, igualdade e direito tributário. São Paulo: Dialética, 1999.

Tributo e solidariedade social. In: (Coords.) GRACO, Marco Aurélio; GODOI, Marciano Seabra.

Solidariedade social e tributação. São Paulo: Dialética, 2005.

HOLMES, Stephen and SUSTEIN, Cass. The Cost of Rights: Why Liberty Depends on Taxes. New York: W. W. Norton and Company, 1999.

KELSEN, Hans. Teoria Pura do Direito. 6a ed. São Paulo: Martins Fontes, 1998.

MARTINS, Ricardo Marcondes. Teoria jurídica da liberdade. São Paulo: Conta Corrente, 2015

MOSCHETTI, Francesco. El principio de la capacidad contributiva. Tradução de Juan M. Calero Gallego y Rafael Navas Vasquez. Madrid: Instituto de Estúdios Fiscales, 1980.

NABAIS, José Casalta. $O$ dever fundamental de pagar impostos - contributo para a compreensão constitucional do estado fiscal contemporâneo. Coimbra: Almedina, 2015.

OLIVEIRA, José Marcos Domingues. Capacidade Contributiva. Conteúdo e Eficácia do Princípio. Rio de Janeiro: Renovar, 1988.

PHILIPPE, Marie-Dominique. Introdução à Filosofia de Aristóteles. São Paulo: Paulus, 2002.

RAWLS, John. O liberalismo político. 2.ed. Tradução de Dinah de Abreu Azevedo. São Paulo: Ática, 2000.

Uma teoria da justiça. Tradução de Jussara Simões. São Paulo: Martins Fontes, 2000.

SANDEL, Michael J. Justiça. O que é fazer a coisa certa. 8a ed. Rio de Janeiro: Civilização Brasileira, 2012.

SILVA, José Afonso. Curso de Direito Constitucional. 32a ed. São Paulo: Malheiros, 2009.

SMITH, Adam. Riqueza das nações. Investigação sobre sua natureza e suas causas. Livro V. v. II. Tradução de Luiz João Baraúna. São Paulo: Nova Cultural, 1996.

STIRN, Fraçois. Compreender Aristóteles. 2a ed. Petrópolis, Rio de Janeiro: Vozes, 2008.

TIPKE, Klaus e YAMASHITA, Douglas. Justiça Fiscal e Princípio da Capacidade Contributiva. São

Paulo: Malheiros, 2002. 